\title{
Selected abbreviations and new terms in breast pathology - a guide for clinicians
}

\author{
Joanna B. Wysocka ${ }^{1}$, Janusz Ryś ${ }^{1}$, Beata Sas-Korczyńska² ${ }^{2}$, Wojciech M. Wysocki
}

The aim of this article is to present briefly new pathological entities which are recently increasingly commonly used in pathology reports, as well as to discuss their clinical consequences. The new WHO classification of breast diseases includes, inter alia, invasive carcinoma of no special type: this is not a specific entity, but rather a group of malignancies without specific features. The lobular hyperplasia group includes a classical variant and a pleomorphic variant of lobular carcinoma in situ, as well as atypical lobular hyperplasia. The ductal hyperplasia group, according to the current revision of the WHO classification of breast diseases, encompasses: typical (i.e. non-atypical) ductal hyperplasia, columnar cell change, columnar cell hyperplasia, atypical ductal hyperplasia. The mesenchymal breast hyperplasia group includes pseudoangiomatous stromal hyperplasia. We briefly discuss the above mentioned entities together with their respective clinical and therapeutic consequences.

NOWOTWORY J Oncol 2017; 67, 4: 257-260

Key words: breast cancer, benign breast disease, atypical lobular hyperplasia, atypical ductal hyperplasia, flat epithelial atypia, pseudoangiomatous stromal hyperplasia

\section{Introduction}

A pathomorphologist is obliged to comply, in histopathological reports, with the terminology applied in the current edition of the breast cancer classification published regularly under the auspices of the World Health Organisation (WHO), which was last updated in 2012 [1]. For the purpose of effective collaboration with other specialists, it is necessary to make the terminology completely understandable and clear for all medical specialists involved in the treatment of breast cancer. It is worthwhile in this context to quote the title of an excellent book written by Juan Rosai discussing the history of pathomorphology in the USA "Guiding the Surgeon's Hand". The pathomorphologist, in order to be able to influence decisions taken by a surgeon, must use the current terminology in their reports and, at the same time, make sure that clinicians correctly interpret this terminology.

The objective of this paper is to present selected new disease entities and terms which have recently appeared in pathological reports, as well as to discuss the consequences of these new entities and terms for patients.

\section{Infiltrating carcinoma NST}

In the current WHO classification the name of the most common histological type of infiltrating breast carcinoma has been changed. It has been recognised that the term which had been used so far, i.e. infiltrating ductal carcinoma is not correct, as it suggests the origin of cancer cells solely from the epithelium lining the ducts of the breast gland, as opposed to the cells of lobular breast cancer (which in turn

\footnotetext{
${ }^{1}$ Department of Tumour Pathology, Maria Skłodowska-Curie Memorial Cancer Centre and Institute of Oncology, Kraków Branch, Poland

${ }^{2}$ Department of Oncology Maria Skłodowska-Curie Memorial Cancer Centre and Institute of Oncology, Kraków Branch, Poland

${ }^{3}$ Department of Surgical Oncology Maria Skłodowska-Curie Memorial Cancer Centre and Institute of Oncology, Kraków Branch, Poland
} 
were supposed to originate from the epithelium within the glandular lobules). In current pathology, there is no evidence for the above statements. Furthermore, it is known that the above term does not define a morphological entity, but rather a group of diverse cancers, which, however, lack any distinctive features (as in the case of e.g. tubular cancer), which would allow for distinguishing a special entity among them - therefore this group was called infiltrating carcinoma of no special type (NST). Thus this is not a new histological type of breast cancer, but a synonym for a previously used term: ductal infiltrating cancer not otherwise specified (NOS). The current WHO classification allows for the use of alternative terms for the same disease, such as ductal carcinoma NST, ductal carcinoma NOS, infiltrating ductal carcinoma, though the use of these terms is not recommended [1].

\section{Lobular hyperplasia}

In the group of lobular hyperplasia, the new classification distinguishes the following morphological entities: classical and pleomorphic lobular carcinoma in situ and atypical lobular hyperplasia. Thus, the group contains all kinds of atypical hyperplasias of glandular epithelium within the terminal duct lobular unit (TDLU) [1].

Atypical lobular hyperplasia (ALH) and lobular carcinoma in situ (LCIS) are not completely separate morphological entities. Atypical lobular hyperplasia and LCIS are rather a continuum of the same lesions, i.e. a hyperplasia of small, monotonous and incohesive epithelial cells within terminal ductal-lobular units (TDLU). The only criterion that distinguishes between ALH and LCIS is the extent of the lobule involvement: if the hyperplasia occupies $<50 \%$ lobule, then a pathomorphologist diagnoses $\mathrm{ALH}$, whilst if the hyperplasia occupies $>50 \%$ lobule, then LCIS is diagnosed. Both diagnoses are breast cancer risk factors, constituting so-called non-obligatory precursors of infiltrating carcinomas, both lobular and NST. What is more, the risk concerns both breasts and not only the one in which the atypical lobular hyperplasia was found. In the case of ALH, the risk of occurrence of infiltrating carcinoma is 4-5 times larger, whilst in the case of LCIS - 8-12 times larger than in the population of women in whose case lobular hyperplasia has never been diagnosed.

It must be stressed that in the case of a diagnosis of ALH and the classical form of LCIS, the WHO classification does not require a pathologist to define the condition and width of surgical margins. Yet in the case where, in accordance with the WHO classification, a pathomorphologist diagnoses one of the variations of LCIS (i.e. pleomorphic LCIS or comedonecrotic LCIS), then, if the lesion was found in a core-needle biopsy, it is necessary to remove the entire cancer focus. This is because the above LCIS variants are accompanied by micro-infiltration or infiltration, and the associated clinical activity should be more aggressive than in the case of classical LCIS [2].

\section{Ductal hyperplasia}

In the group of ductal hyperplasia, the WHO classification distinguishes, inter alia, usual (i.e. not atypical) ductal hyperplasia (UDH), various columnar cell changes or columnar cell hyperplasia or flat epithelial atypia, (FEA) and atypical ductal hyperplasia (ADH) [1].

Within the terminal end of a ductal-lobular unit, there might develop some morphological lesions made up from columnar cells - increased, frequently dilated glandular lobules and terminal ductules lined with epithelial columnar cells, yet without any features of nuclear atypia. In accordance with the definition, if only 1 layer of columnar cells is found, then a columnar cell change is diagnosed, whilst if more than 1 layer of columnar cells is found, then columnar cell hyperplasia must be diagnosed. Such lesions frequently accompany benign lesions in the breasts (such as cysts and UDH) and lobular hyperplasias; they are accompanied by microcalcifications. Moreover, the described lesions frequently co-exist with LCIS/ALH and tubular breast cancer [3]. Columnar cells lesions and hyperplasias increase the risk of breast cancer development only to a slight degree (about 1.5 times).

The cells of a columnar cell lesion may have some slight cytological atypia. Then a pathomorphologist diagnoses flat epithelial atypia (FEA). In the microscopic image there are one or more layers of cells which do not make up atypical structures, but are characterised by a typical nuclear atypia (of low grade type). The synonym which WHO allows here is columnar cell hyperplasia/change with atypia (FEA).

There is a strong correlation between FEA and the presence of lobular hyperplasia (LCIS/ALH), atypical ductal hyperplasia (ADH), low grade DCIS [3] and low grade infiltrating cancers. The risk of their development into infiltrating carcinoma is small (smaller than in the case of ALH and ADH). In the case of an FEA diagnosis in core needle biopsy material, in accordance with the recommendations listed in the WHO classification, the clinical course is not definitively determined and depends, inter alia, upon the level of correlation of radiological and pathological evaluation, whilst the surgical recommendations are more precise: it is recommended either to place the patient under strict clinical observation or qualify them for a complete resection of the focus [2].

Atypical ductal hyperplasia (ADH), in accordance with the WHO classification, means a hyperplasia of monomorphic epithelial cells within a terminal duct lobular unit. The microscopic picture reveals both a cytological atypia and a disorder (in other words - atypia) of a structural type (usually distinctly marked). The main criterion distinguishing between ADH and low grade DCIS is the extent of the lesion: the involvement of $>2$ neighbouring ducts or a size 


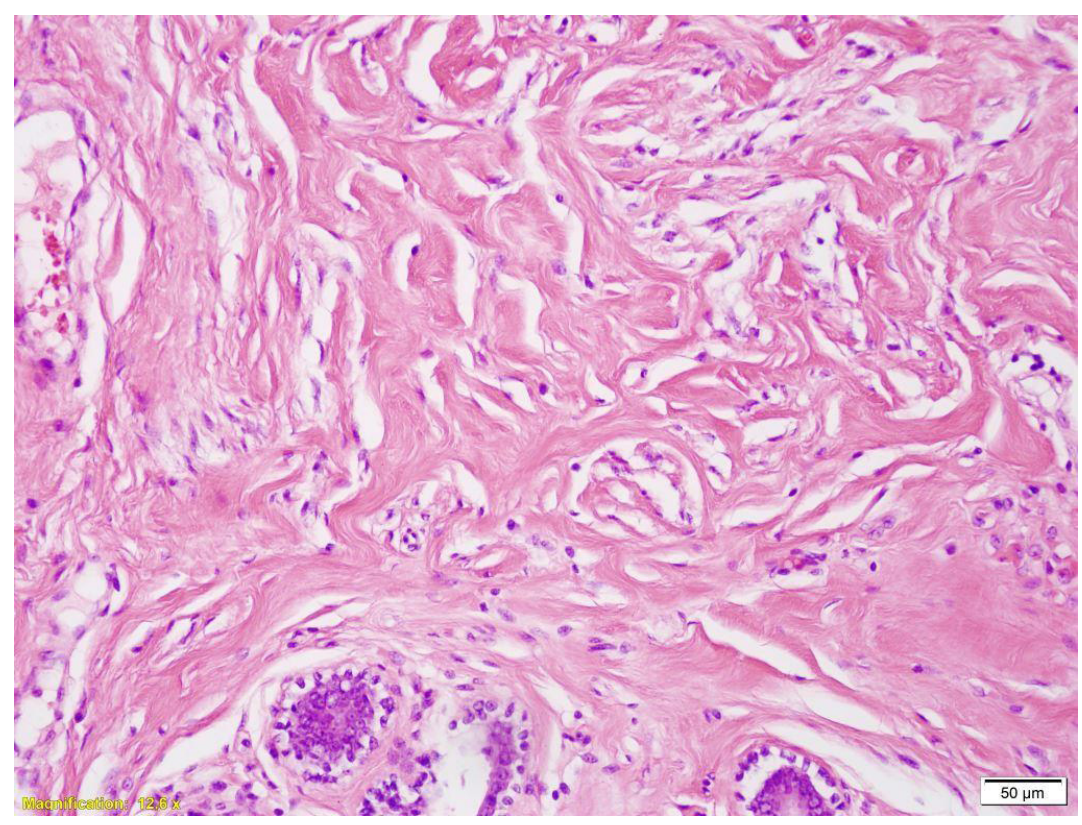

Figure 1. Pseudoangiomatous stromal hyperplasia (PASH) the cells lining the spaces here are characterised by the presence of small nuclei without any properties of atypia. No mitotic division figures are observed. HE staining, $200 \times$ magnification

of $r>2$ mm allows a diagnosis of low grade DCIS. Unfortunately, the evaluation of this criterion leads to some doubt in cases where the specimen comes from a core needle biopsy. The risk of breast cancer involvement in the case of $A D H$ is 3-5 times larger than in the general population. This is why, the treatment should consist - in the case of a core needle biopsy diagnosis of $A D H$ - of the removal of the lesion. If, however, the presence of $A D H$ is found in the resection margin after the cancer removal, then there are no grounds for surgical radicalisation. In accordance with the recommendation of the National Comprehensive Cancer Network (NCCN), the presence of ADH in the resection margin of another, benign breast lesion may (but does not have to) lead to a surgical radicalisation [4]. In the case of such a lesion, it is also recommended to administer chemo-prevention, yet in practice, this is rarely used [5].

\section{Mesenchymal stromal hyperplasia}

In this group of lesions, the current WHO classification [1] lists pseudoangiomatous stromal hyperplasia (PASH), which is defined as a benign hyperplasia of myofibroblasts in the glandular stroma, taking the morphological form of slit-like (pseudovascular) spaces lined with spindle cells (Fig. 1). A characteristic property of PASH is a correlation with hormonal imbalance (e.g. before menopause or in the period of puberty in men), the use of hormonal contraception or HRT. The radiological image does not reveal any microcalcifications, but PASH may form a clinically visible tumour. The treatment is not definitively specified, but the lesion may be closely watched after verification with a core needle biopsy, if there is no clinical doubt or clinical symptoms. Otherwise tumour resection should be considered $[6,7]$.

\section{Conclusions}

The terminology used in pathomorphological reports should be unambiguous and understandable for clinicians who, on the basis of that report, take decisions concerning the treatment options (or the abandonment of active treatment). The objective of this short paper was to present the typical abbreviations (such as ALD, UDH, FEA, ADH, PASH) which are frequently quoted in current national pathological reports describing tissue specimens as well as the clinical significance of the lesions described in such reports.

Conflict of interest: none declared

\author{
Joanna B. Wysocka, MD \\ Department of Tumour Pathology \\ Maria Skłodowska-Curie Memorial Cancer Centre \\ and Institute of Oncology \\ Kraków Branch \\ Garncarska St. 11 \\ 31-115 Kraków, Poland \\ e-mail:jwysocka@mp.pl
}

Received: 4 Jun 2017

Accepted: 9 Jun 2017

The paper was written on the basis of a lecture delivered by the first author of the text during the $5^{\text {th }}$ Winter Oncological Forum organised by the Polish Society of Oncological Surgery in Zakopane in January 2017. 


\section{References}

1. WHO classification of tumours of the breast. $4^{\text {th }}$ ed. Lakhani SR, Ellis IO, Svhnitt SJ (eds.). Lyon: IARC, 2012.

2. Chirurgiczne leczenie zmian nowotworowych piersi: konsensus Polskiego Towarzystwa Chirurgii Onkologicznej. Nowecki Z, Jeziorski A (eds.). Gdańsk: Via Medica, 2016.

3. Chmielik E. Nowe i kontrowersyjne jednostki morfologiczne w patologii gruczołu piersiowego. Polish J Pathol 2014; 65 (4 Supl. 2): S42-52.
4. National Comprehensive Cancer Network. (NCCN) Guidelines. Breast Cancer v2.2017; www.ncen.org.

5. Hartmann LC, Degnim AC, Santen RJ et al. Atypical hyperplasia of the breast — riskassessment and management options. NEng JMed 2015;372: 78-89.

6. Jaunoo SS, Thrush S, Dunn P. Pseudoangiomatous stromal hyperplasia (PASH): A brief review. Int J Surg 2011; 9: 20-22.

7. Deniz S, Vardar E, Öztürk R et al. Pseudo-angiomatous stromal hyperplasia of the breast detecting in mammography: case report and review of the literature. Breast Dis 2014; 34: 117-120. 